Research Article

\title{
The Modeling Research on the Early-Age Shrinkage of UHPFRC in Different Curing Conditions
}

\author{
Song Han (D, Yazhou Liu, Dan Liu, Mingzhe An, and Ziruo Yu \\ School of Civil Engineering, Beijing Jiaotong University, Beijing 100044, China \\ Correspondence should be addressed to Song Han; songhan@bjtu.edu.cn
}

Received 2 February 2018; Accepted 5 June 2018; Published 11 July 2018

Academic Editor: Flora Faleschini

Copyright (c) 2018 Song Han et al. This is an open access article distributed under the Creative Commons Attribution License, which permits unrestricted use, distribution, and reproduction in any medium, provided the original work is properly cited.

The early-age shrinkage of ultra-high performance fiber reinforced concrete (UHPFRC) in dry, sealed, and soaked curing was systematically measured. The calculation model of early-age shrinkage was established based on the theory of shrinkage of cementitious materials. According to the results of the relative humidity, hydration degree, pore structure, and elastic modulus of hardened slurry, the shrinkage calculation model in different curing conditions was calibrated. The results show that the early-age shrinkage of UHPFRC can be divided into three parts: chemical shrinkage, autogenous shrinkage caused by self-drying, and drying shrinkage caused by external drying. Based on the degree of hydration, the chemical shrinkage model was established. Based on the pore structure, the hydration degree, and the relative humidity of hardened slurry, the autogenous shrinkage model was established by introducing the effective pore coefficient. The drying shrinkage model was established based on the internal humidity. According to the shrinkage of soaked samples, the calculated value of chemical shrinkage in sealed and drying conditions was calibrated. This research provides theoretical support for the structural design and engineering application of UHPFRC.

\section{Introduction}

Ultra-high performance fiber reinforced concrete (UHPFRC), a special cement-based composite material, can be used as structural or protective material used in harsh environments in long-term service of important projects, due to its excellent mechanical properties and durability. In recent years, it has become a hot spot for researchers $[1,2]$, and there have been a lot of engineering applications. In China, UHPFRC is now used in pavement system, which significantly improved the mechanical properties and durability of composite bridge deck system. UHPFRC is also used in prefabricated components, such as cable trench, cover plate, and wind barrier in high speed railway, bus station, and rest pavilion in urban area, and so on. UHPFRC is generally composed of cement, mineral admixtures, steel fiber, fine aggregate, and chemical admixtures [3]. UHPFRC is designed with the compact packing model, removing the coarse aggregate and adopting the ultra-low water-cement ratio, increasing the amount of the binder material and incorporating the active admixture.
Active admixture such as silica fume reacts with cement at early age of UHPFRC, which could optimize the pore structure and greatly reduces internal defects of the hardened slurry [4]. Active admixtures and ultra-low water-cement ratio ensures excellent mechanical properties and durability, and it also brought a large early-age shrinkage, which may cause a significant risk of cracking. The results of existing studies show that the total shrinkage value of the UHPFRC in $3 \mathrm{~d}$ (day) can be as high as $1600 \mu \varepsilon$ [5] (micron epsilon), while the curing condition has a significant effect on the shrinkage of the material. The existing research mostly focus on the early-age shrinkage of ordinary concrete (OC) and establish a perfect shrinkage calculation model for autogenous shrinkage and drying shrinkage [6]. However, the early-age shrinkage development rules and micromechanism of UHPFRC have not yet been clarified [7], and the computational model is also less involved in the study. Ishida et al. [8] tried to use the concrete shrinkage cracking model to calculate the early-age shrinkage cracking of the silica-doped concrete with very low water-cement ratio. The result showed that the 
shrinkage model of OC cannot accurately calculate the shrinkage value of UHPFRC. In addition, some studies focused on the regularity of the early-age shrinkage of the UHPFRC based on the existing shrinkage measurement method of OC $[9,10]$, and the shrinkage mechanisms they proposed also had significant divergences.

Therefore, the shrinkage mechanism of UHPFRC is investigated, and the calculation model of early-age shrinkage is established, which can provide the theoretical basis for the structural design and engineering application of UHPFRC. In this investigation, the early-age shrinkage tests of UHPFRC in different curing conditions were carried out, and the early-age shrinkage development of materials in soaking, sealing, and drying conditions was clarified. Based on the basic theory of chemical shrinkage, autogenous shrinkage and drying shrinkage of OC, this paper discussed the classification and definition of the early-age shrinkage of the UHPFRC and clarified the main influencing factors of different shrinkage. By measuring the internal relative humidity, hydration degree, elastic modulus, and pore structure characteristics of different age materials in different curing conditions, based on the early-age shrinkage theory of cement-based materials, the calculation model of multifactor impact has been established, which provides theoretical support for the UHPFRC structure design and engineering applications.

\section{Materials and Methods}

2.1. Materials. An ordinary Portland cement (fineness $3400 \mathrm{~cm}^{3} / \mathrm{g}$; the initial set $160 \mathrm{~min}$, final set $220 \mathrm{~min}$, and $28 \mathrm{~d}$ standard strength $42.5 \mathrm{MPa}$ ) is used for cementitious materials. Its clinker mineral compositions are shown in Table 1. The silica fume with average particle size of $0.31 \mu \mathrm{m}$, I-grade fly ash, and S95 mineral powder are used as supplementary cementitious materials. The chemical compositions are shown in Table 2. Quartz sand with particle size $0.16-1.25 \mathrm{~mm}$ is used as fine aggregate. Short-cut steel fiber with the diameter of $0.22 \mathrm{~mm}$, length $13 \mathrm{~mm}$, and tensile strength of $2800 \mathrm{MPa}$ is used as reinforced material. PCE with $29 \%$ water reduction rate and $31 \%$ solid content is used as superplasticizer.

The concrete mix design is calculated according to the formula of UHPFRC commonly used in this research team, including cement $706 \mathrm{~kg} / \mathrm{m}^{3}$, quartz sand $1255 \mathrm{~kg} / \mathrm{m}^{3}$, silica fume $160 \mathrm{~kg} / \mathrm{m}^{3}$, superplasticizer $74 \mathrm{~kg} / \mathrm{m}^{3}$, water $122 \mathrm{~kg} / \mathrm{m}^{3}$, and steel fiber $122 \mathrm{~kg} / \mathrm{m}^{3}$. The compressive strength of UHPFRC in standard curing and steam curing was $115 \mathrm{MPa}$ and $165 \mathrm{MPa}$, respectively. In the chemical combined water, the mercury intrusion porosimetry method (MIP) and other microtest, the use of samples removing quartz sand can comply with the requirements of sample preparation to the utmost extent.

2.2. Test Methods. The early-age shrinkage test references to the current Chinese Code GB/T50082-2009 (Ordinary Concrete Long-term Performance and Durability Test Method Standard). The specified specimen size is $100 \mathrm{~mm} \times 100 \mathrm{~mm} \times 400 \mathrm{~mm}$, curing at $25^{\circ} \mathrm{C}$ temperature in soaking, sealing, and drying
TABle 1: The primary mineral composition of 42.5 ordinary Portland cement wt.\%.

\begin{tabular}{ccccccc}
\hline & $\mathrm{C}_{3} \mathrm{~S}$ & $\mathrm{C}_{2} \mathrm{~S}$ & $\mathrm{C}_{4} \mathrm{AF}$ & $\mathrm{C}_{3} \mathrm{~A}$ & $\mathrm{f}-\mathrm{MgO}$ & $\mathrm{f}-\mathrm{CaO}$ \\
\hline Mass percentage & 60.5 & 18.1 & 8.9 & 7.4 & 1.8 & 0.9 \\
\hline
\end{tabular}

TABle 2: The chemical composition of silica fume, class I fly ash, and S95 slag wt.\%.

\begin{tabular}{lcccccccc}
\hline & $\mathrm{SiO}_{2}$ & $\mathrm{Fe}_{2} \mathrm{O}_{3}$ & $\mathrm{Al}_{2} \mathrm{O}_{3}$ & $\mathrm{CaO}$ & $\mathrm{MgO}$ & $\mathrm{SO}_{3}$ & $\begin{array}{c}\text { Alkali } \\
\text { content }\end{array}$ & Loss \\
\hline $\begin{array}{l}\text { Silica } \\
\text { fume }\end{array}$ & 82.22 & 1.81 & 0.97 & 0.36 & 1.31 & 0.27 & 1.09 & 1.45 \\
$\begin{array}{l}\text { Fly ash } \\
\begin{array}{l}\text { Mineral } \\
\text { powder }\end{array}\end{array}$ & 52.7 & 25.8 & 9.7 & 3.7 & 1.2 & - & 2.30 & 0.4 \\
\hline
\end{tabular}

curing, respectively. The high-precision vibrating wire sensors (JMZX-215HAT type) are used to continuously measure the shrinkage of UHPFRC. The shrinkage value is read every 24 hours until $28 \mathrm{~d}$. According to the previous research of this research team, this method can accurately measure the early-age shrinkage of the specimen in special curing conditions [11]. The SHT75 temperature and humidity sensors buried in the center of the specimen $(100 \mathrm{~mm} \times 100 \mathrm{~mm} \times 100 \mathrm{~mm})$ are used to measure the internal humidity changes; the internal humidity of the hardened slurry is read with the SCTH2001 data collector every 24 hours from the pouring time. According to current Chinese Code GB/T50081-2002 (standard test method for mechanical properties of common concrete), the elastic modulus test was carried out using $100 \mathrm{~mm} \times 100 \mathrm{~mm} \times 300 \mathrm{~mm}$ prism specimen with YA-2000 electrohydraulic pressure testing machine in the sealing and drying conditions.

The hydration degree was carried out by the hydration heat test and chemical combined water test. The TAM AIR multichannel hydration heat measuring instrument, used to place the mixed cement slurry in the TAM equipment measurement tank, could continuously measure the exotherm rate of cement paste hydration in $7 \mathrm{~d}$. The samples of chemical combined water test were selected at 1, 3, 7, 14, and $28 \mathrm{~d}$. After vacuum drying to constant weight at $60^{\circ} \mathrm{C}, 10 \mathrm{~g}$ samples were accurately weighed (accuracy: $0.1 \mathrm{mg}$ ) and dried to constant weight at $1050^{\circ} \mathrm{C}$. The chemical combined water of the sample was calculated by two weight differences.

\section{Results and Discussions}

3.1. Early-Age Shrinkage of UHPFRC. The early-age shrinkage of UHPFRC with selected mixing was measured in different curing conditions, as shown in Figure 1. The shrinkage of UHPFRC showed a rapid development in the early stage and a gradual slowdown later. In the soaking and drying conditions, the material shrinkage developed rapidly before $6 \mathrm{~d}$, and then shrinkage curve tended to be gentle. According to the mechanisms, the shrinkage of the hardened slurry in $28 \mathrm{~d}$ could be divided into three parts [12]: chemical shrinkage $\left(\varepsilon_{a}\right)$ due to hydration of the cementitious material, drying shrinkage $\left(\varepsilon_{b}\right)$ caused by 


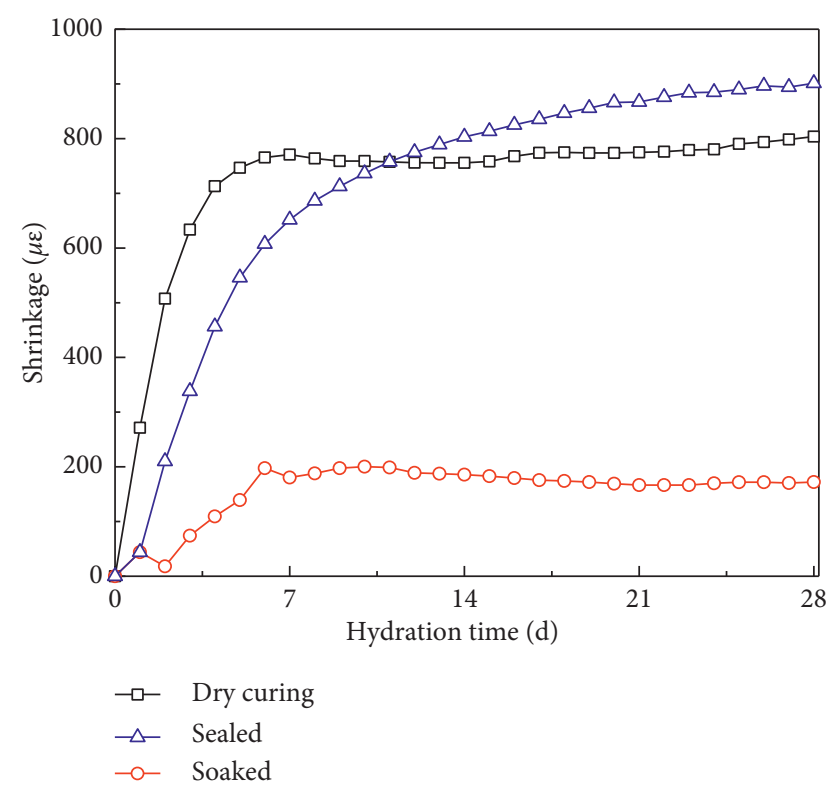

FIGURE 1: $28 \mathrm{~d}$ shrinkage of hardened slurry in different curing conditions.

external drying, and autogenous shrinkage $\left(\varepsilon_{c}\right)$ due to selfdrying effect caused by hydration.

The chemical shrinkage depends on the hydration degree of the material, and the drying shrinkage depends on the pore structure and the internal relative humidity of the hardened slurry, while the autogenous shrinkage is determined by the hydration degree, the pore structure, and the internal relative humidity. Therefore, considering the main factors affecting the material shrinkage, the internal relative humidity, hydration degree, pore structure distribution, and elastic modulus of the hardened slurry were measured in different curing conditions, the results of which are shown in Figure 2. It was obvious that the composition of the material shrinkage would be also different in different curing conditions. The shrinkage of UHPFRC was mainly chemical shrinkage in soaking condition. According to Figure 2(a), although the early-age moisture has not completely immersed inside the concrete, the humidity curve still showed a significant descent, which indicated the existence of partial autogenous shrinkage, while the internal humidity increased slowly when the moisture gradually reached the inside of specimen after $7 \mathrm{~d}$. In the sealing condition, the material shrinkage consists of chemical shrinkage and autogenous shrinkage due to the exclusion of external drying. However, the shrinkage composes of chemical shrinkage, autogenous shrinkage, and dry shrinkage in drying conditions. Based on the shrinkage theory of cementitious material, the calculation model was established for different kinds of shrinkage. It was worth noting that the shrinkage of UHPFRC in sealing condition was even higher than that in drying condition after 11 days. This rule is contrary to the shrinkage development of OC, which has been discussed by this research group in the preliminary work [13]. The shrinkage value in sealing condition would grow continuously and be even higher than that in drying condition later, which is due to the differences of the effective pore content and stiffness change.

3.2. Calculation Method of Chemical Shrinkage. Hydration of cementitious materials is the direct cause of chemical shrinkage. At present, the relation between cement hydration degree and chemical shrinkage in OC has been studied systematically $[14,15]$, which concluded that there was a linear relationship between them in the early stage of shrinkage. Thence the cement hydration degree could be viewed as the quantitative analysis index of chemical shrinkage.

According to the results of relative humidity test, the humidity inside UHPFRC was always close to $100 \%$ within $1 \mathrm{~d}$ in sealing condition. It could be seen that the internal pores were basically saturated, which meant that the effects of drying shrinkage and autogenous shrinkage were negligible. Therefore, the shrinkage of UHPFRC was mainly the chemical shrinkage within $1 \mathrm{~d}$, and the shrinkage curve could be fitted with the hydration degree to obtain the relationship between the hydration degree and the chemical shrinkage of UHPFRC. It was also used to calibrate the proportion of chemical shrinkage in different conditions. Through the hydration heat test to determine the hydration degree in early age, the hydration degree of cementitious materials in the concrete was defined as

$$
\alpha(t)=\frac{Q(t)}{Q_{\max }},
$$

where $Q(t)$ is the hydration heat release amount at time $t$ and $Q_{\max }$ is the total release amount of hydration heat.

The hydration degree and the shrinkage strain within 24 days were calculated by linear fitting to obtain

$$
Y=\left\{\begin{array}{ccc}
-2.68+10.24 \alpha & (5>a>0) & (R=0.992) \\
36.05+2.15 \alpha & (a>5) & (R=0.984)
\end{array}\right.
$$

where $\alpha$ is the hydration degree of cementitious material, the unit $\%$.

The linear relationship between the chemical shrinkage and the hydration degree is shown in Figure 3. The slope of linear relationship changed abruptly when the hydration degree reached about $5 \%$ (scilicet, the hydration time at about $17 \mathrm{~h}$ ), indicating that the microstructure of slurry changed greatly at the dividing point. According to the early hydration heat release curve of UHPFRC in Figure 2(c), $17 \mathrm{~h}$ was the beginning of the slurry hydration acceleration period and the time of slurry condensation. The slurry changed from plastic to nonplastic at this moment. In the plastic phase, the chemical shrinkage of slurry was in the form of plastic shrinkage, but after that moment, part of chemical shrinkage caused the shrinkage of slurry skeleton, and the other part formed internal porosity, which caused the internal pores beginning to form; wherefore, a two-stage chemical shrinkage 


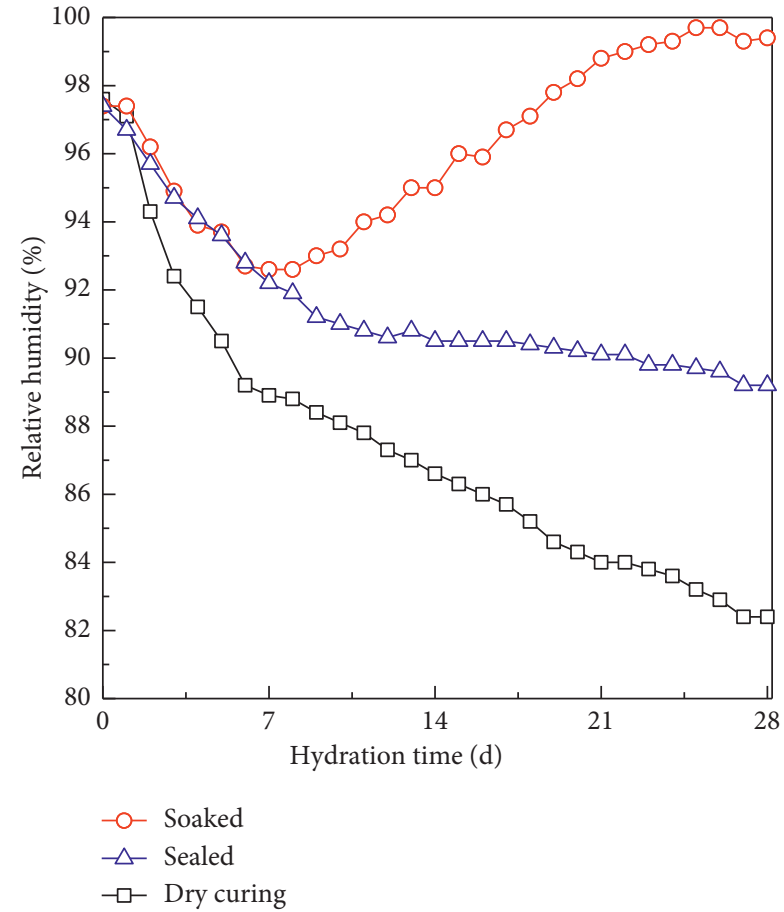

(a)

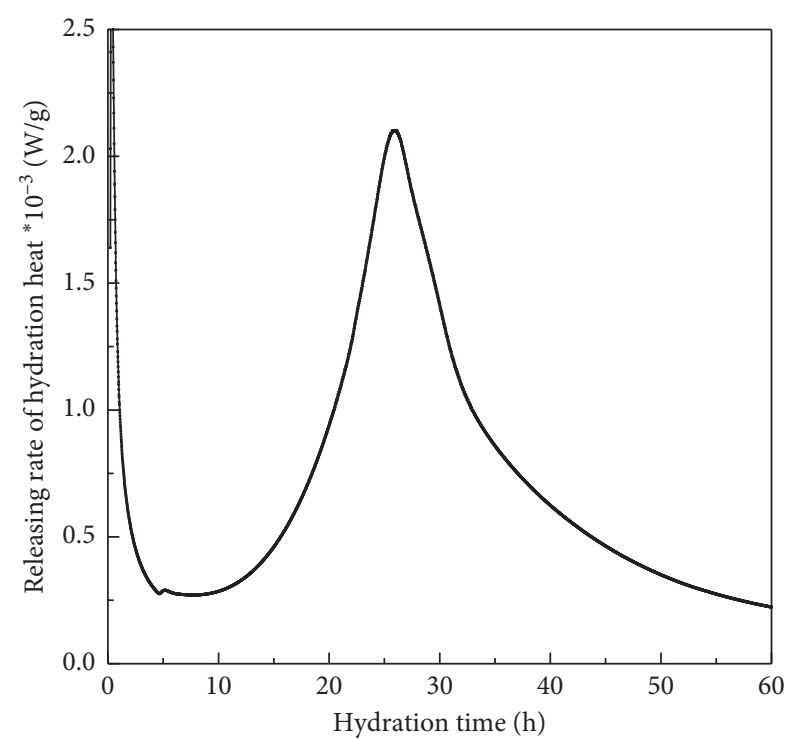

(c)

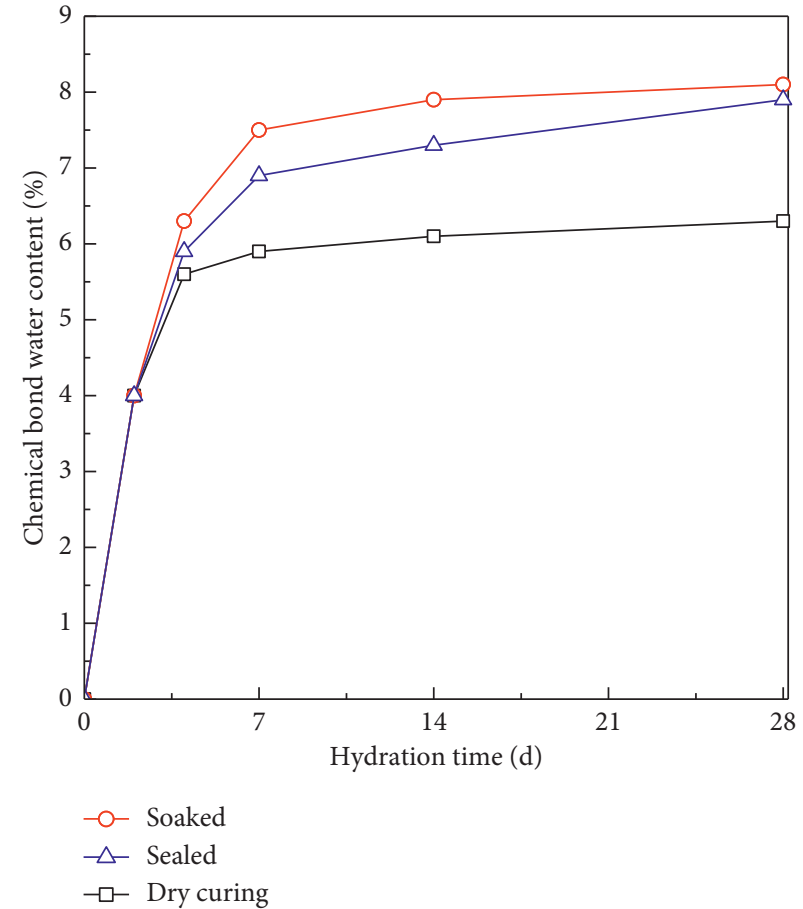

(b)

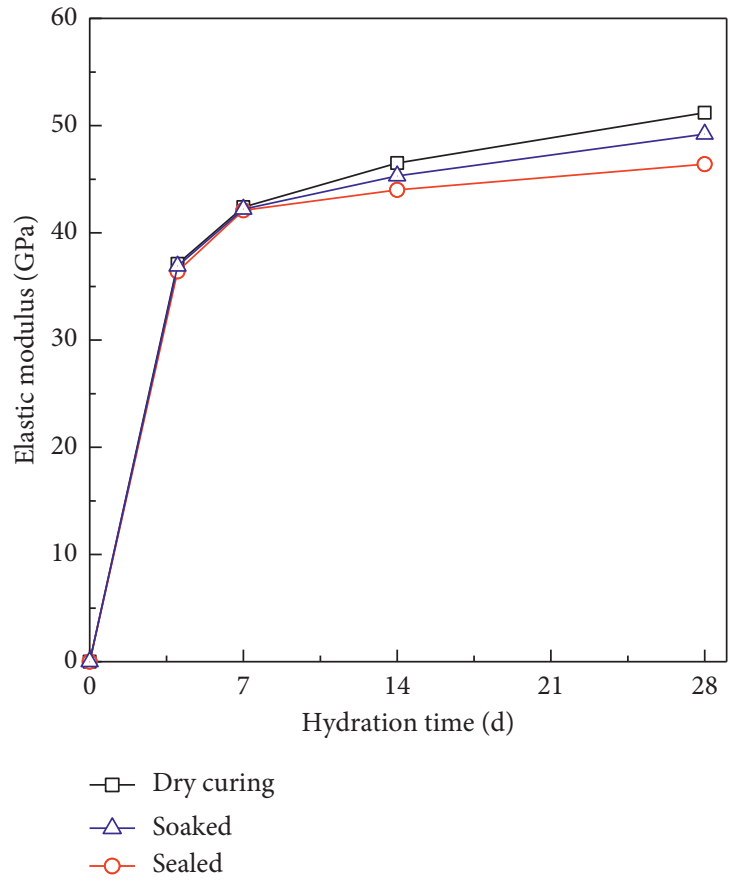

(d)

Figure 2: The chemical bond water, elastic modulus, relative humidity, and hydration heat of hardened slurry. (a) Relative humidity. (b) Chemical bond water. (c) Hydration heat. (d) Elastic modulus.

development was formed. According to the linear relationship, the chemical shrinkage values could be calculated with the hydration degree obtained by the chemical combined water test in 28 days in different conditions. So far, we calculated the chemical shrinkage of UHPFRC with the hydration degree of material in different curing conditions, and the results are shown in Figure 4.

3.3. Calculation of Autogenous Shrinkage. On the basis of mastering the chemical shrinkage, the autogenous shrinkage 


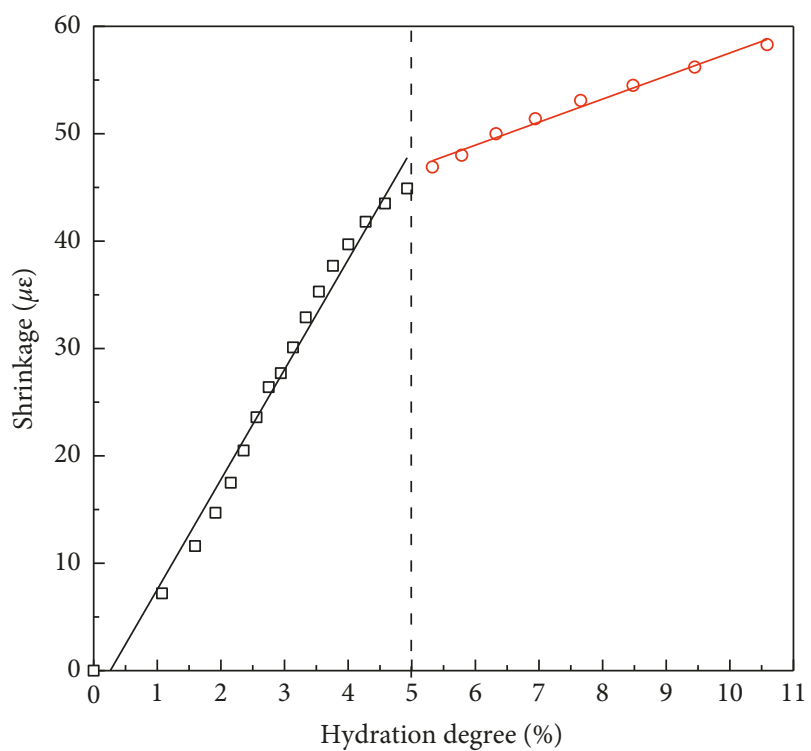

Figure 3: The fitting curve of hydration degree and chemical shrinkage.

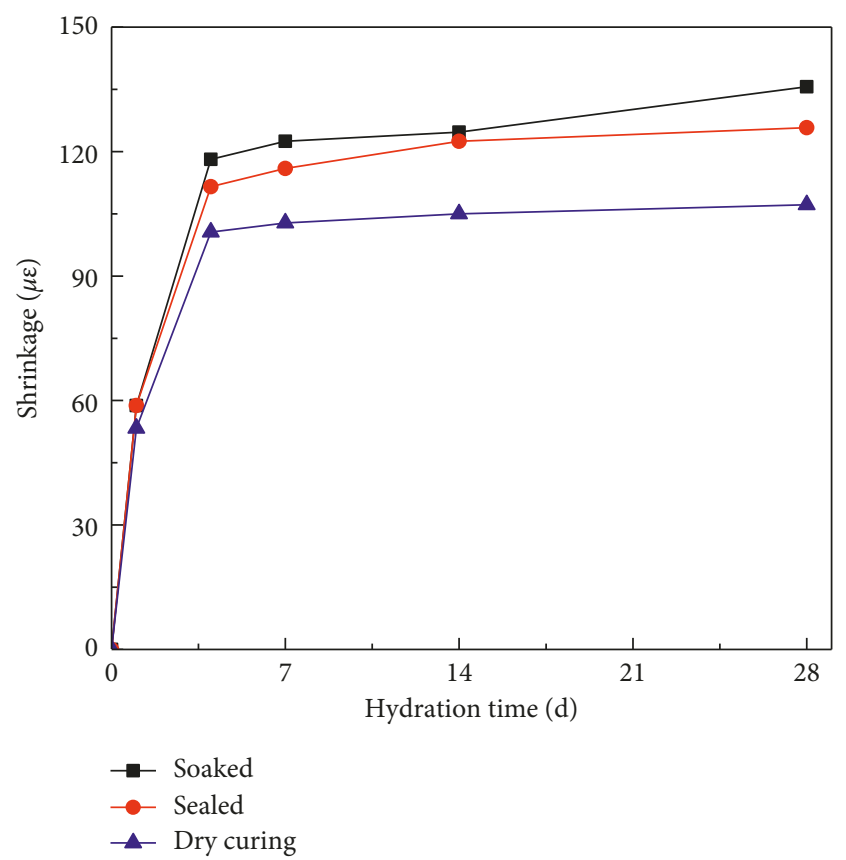

FIGURE 4: The chemical shrinkage of UHPFRC in different curing conditions.

of UHPFRC was further separated. In this study definition, the autogenous shrinkage caused by the self-drying effect is somewhat different from the concrete autogenous shrinkage in the conventional concept. The traditional concept of autogenous shrinkage refers to the use of sealing specimens to start measuring the shrinkage value from the initial setting time, including chemical shrinkage and drying shrinkage caused by self-dry hydration; in this investigation, chemical shrinkage will be separated, and the remainder is named autogenous shrinkage. In the UHPFRC, the main influencing factors of autogenous shrinkage were the humidity change caused by hydration of cementitious materials and the pore structure of hardened slurry. The shrinkage mechanism could be regarded as the drying shrinkage caused by self-drying. Therefore, the establishment of selfshrinkage prediction model was based on the theory of capillary tension. In the sealing condition, the shrinkage of UHPFRC was mainly chemical shrinkage and autogenous shrinkage at $25^{\circ} \mathrm{C}$. Since the moisture could not dissipate out, the drying shrinkage caused by external drying was ruled out. Based on the autogenous shrinkage value, removed chemical shrinkage in sealing condition, combined with the parameters of pore size distribution, internal relative humidity, hydration degree, and elastic modulus, the autogenous shrinkage model of UHPFRC, was established and the proportion of autogenous shrinkage was calculated in drying conditions.

According to the Powers capillary tension theory [16], the model was based on two basic equations of surface physical chemistry, namely, Kelvin equation and Yang-Laplace equation. In the light of Kelvin's law, when the humidity in the concrete begins to decrease, the evaporable water and the gaseous water are in the thermodynamic balance. The relationship between the relative humidity $\mathrm{RH}$ and the curvature radius $r$ of the capillary pores meniscus is as follows:

$$
\mathrm{RH}=\exp \left(\frac{-2 \gamma M \cos \theta}{\rho r R T}\right) .
$$

In the formula, $\gamma$ is the surface tension of the capillary inner wall, $7.28 \times 10^{-2} \mathrm{~N} / \mathrm{m} ; M$ is the molar mass of water, $0.01802 \mathrm{~kg} / \mathrm{mol} ; \theta$ is the contact angle of solid-liquid surface; $\rho$ is the density of water, $1 \times 10^{3} \mathrm{~kg} / \mathrm{m}^{3}$; $R$ is the molar gas constant, $8.314 \mathrm{~J} / \mathrm{mol} \cdot \mathrm{K} ; \mathrm{T}$ is the absolute temperature.

The initial internal relative humidity of the fresh UHPFRC was $100 \%$. With the rapid hydration of cement, the relative humidity decreased gradually. When the thermodynamic balance was reached inside the pore, the relative humidity corresponded to a capillary water curvature radius $r_{\mathrm{RH}}$. At this point within the system, the pores with pore diameters greater than $r_{\mathrm{RH}}$ did not have liquid water inside and produce capillary tension, but pores with pore diameters less than $r_{\mathrm{RH}}$ were opposite exactly. Therefore, the moisture in the concrete macroporous began to dry firstly, gradually transitioning to the keyhole, and the relative humidity also decreases at the same time. According to the Kelvin equation and the Yang-Laplace equation, the curvature radius $r_{\mathrm{RH}}$ of the capillary pores meniscus at a certain relative humidity is as follows:

$$
r_{\mathrm{RH}}=\frac{-2 \gamma M}{\ln (\mathrm{RH}) \rho R T} .
$$

Based on the Yang-Laplace equation, the pressure difference between the liquid phase and the gas phase is caused by the meniscus of capillary water. Therefore, the shrinkage stress produced by the pores can be calculated as

$$
\sigma=\frac{2 \gamma}{r_{\mathrm{RH}}}=-\frac{\ln (\mathrm{RH}) \rho R T}{M} .
$$




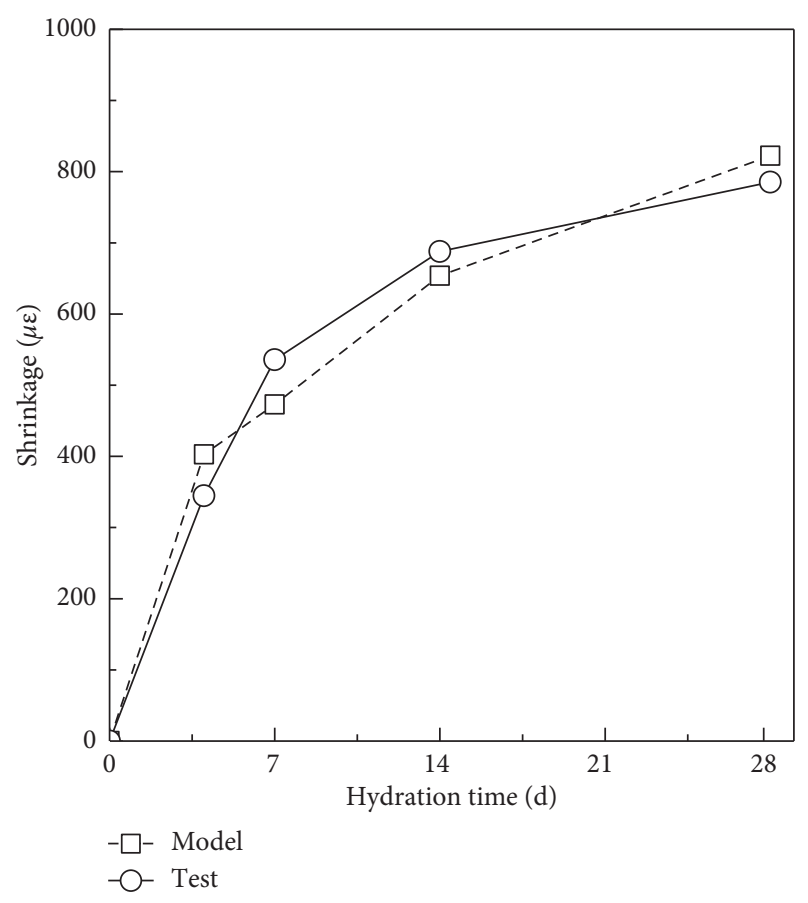

FIGURE 5: Comparison between calculated and measured values of shrinkage model.

The strain caused by the capillary pores tension can be obtained by

$$
\varepsilon=-\xi \frac{1-2 \mu}{E_{\mathrm{s}}} \cdot \frac{\ln (\mathrm{RH}) \rho R T}{M}
$$

Among them, $\mu$ is Poisson's ratio of UHPFRC; $E_{\mathrm{s}}$ is the elastic modulus of the micromatrix around the capillary; the ratio of the elastic modulus $\mathrm{E}$ to Es is usually between 3 and $3.5\left(E / E_{\mathrm{s}}=3\right.$ for low-strength concrete and $E / E_{\mathrm{s}}=3.2$ for highstrength concrete); and $\xi$ is the effective pore coefficient.

In the sealing condition, the relative humidity decreased and the hydration degree increased continuously with the progress of hydration. Although the proportion of capillary pores in 10-100 $\mathrm{nm}$ increased, the number of effective pores decreased with the drop of relative humidity. The effect of effective hole on shrinkage could not be neglected, so an effective pore coefficient $\xi$ was introduced in the autogenous shrinkage prediction model for correction. The number of effective pores was affected by relative humidity and the pore content in the range of $10-100 \mathrm{~nm}$; wherefore, the effective pore coefficient should be a function with these two factors as the dependent variable. With reference to the existing shrinkage calculation model of cement-based material, the power function was used to fit. The relationship between the effective pore coefficient $\xi$ and the relative humidity RH and the pore content $W$ is given by (7). The coefficients in the formula can be obtained by inversion of the concrete shrinkage data, where $\lambda$ and $\eta$ are 0.57 and 0.77 , respectively. Substituting the different age porosity coefficients calculated by (7) in (6) yields the shrinkage strain at different ages. Figure 5 shows the comparison between the models calculated values of different age and the measured values after

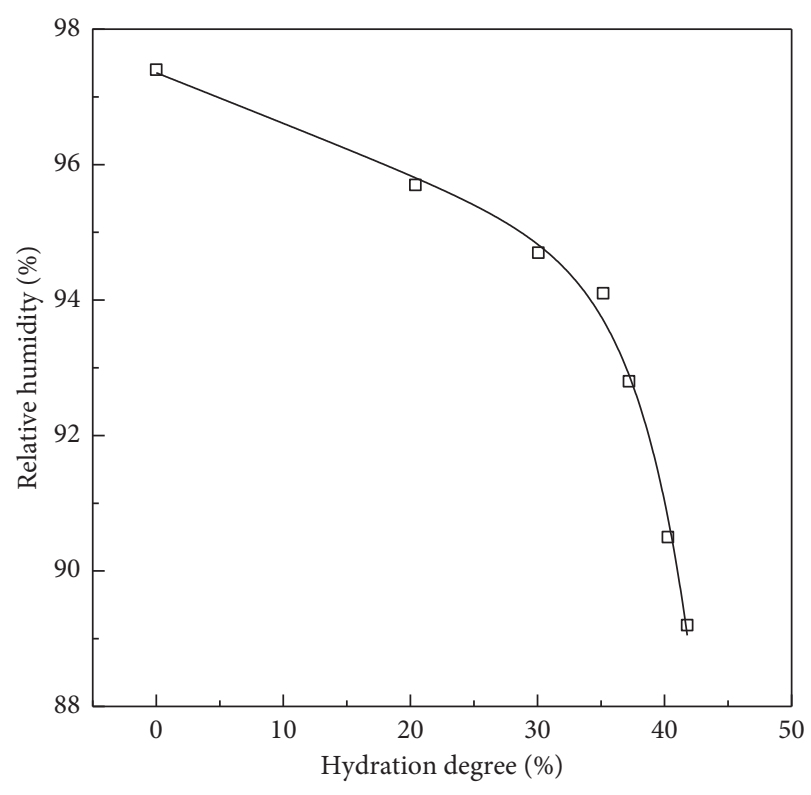

FIgURE 6: The relationship of hydration degree and relative humidity in sealed curing.

TABLE 3: The relative humidity corresponding to different hydration degree in dry curing.

\begin{tabular}{lcccc}
\hline Age $(\mathrm{d})$ & 4 & 7 & 14 & 28 \\
\hline Hydration degree (\%) & 30.07 & 31.09 & 32.11 & 33.13 \\
Relative humidity (\%) & 94.80 & 94.64 & 94.46 & 94.25 \\
\hline
\end{tabular}

subtracting chemical shrinkage, which indicates that the calculated results are in good agreement with the measured results.

$$
\xi=\lambda *(W \cdot \ln \mathrm{RH})^{\wedge} \eta .
$$

Based on the autogenous shrinkage calculation model, according to the early-age shrinkage measured value of UHPFRC in drying conditions and autogenous shrinkage calculation model, the autogenous shrinkage of the material in drying conditions can be separated. In drying conditions, there were two reasons for water loss inside UHPFRC; one of them was that the hydration of the cementitious material consumed water and the other was that the water lost to environment continuously. The hydration of cementitious material reduced the moisture content, which was the underlying cause of the humidity drop inside the material. Therefore, the relationship between the hydration degree of cementitious material and the relative humidity change inside the material was established. The hydration degree in the 28 days was nonlinearly fitted with the relative humidity in sealing condition, as shown in Figure 6. Substituting the hydration degree of different ages in drying conditions, the relative humidity change value corresponding to the hydration degree could be calculated, the calculation results of which are shown in Table 3.

The relative humidity values in Table 3 were taken into (6) to obtain the autogenous shrinkage values in drying conditions, and the autogenous shrinkage calculated values 
TABLE 4: Comparison between the calculated value of autogenous shrinkage and total shrinkage in dry curing.

\begin{tabular}{lccc}
\hline Time $(\mathrm{d})$ & $\begin{array}{c}\text { Autogenous } \\
\text { shrinkage }(\mu \varepsilon)\end{array}$ & $\begin{array}{c}\text { Total } \\
\text { shrinkage }(\mu \varepsilon)\end{array}$ & $\begin{array}{c}\text { The proportion } \\
\text { of autogenous } \\
\text { shrinkage }(\%)\end{array}$ \\
\hline 4 & 346.8 & 713.1 & 48.63 \\
7 & 342.8 & 770.7 & 44.48 \\
14 & 357.7 & 755.6 & 46.17 \\
28 & 364.4 & 803.6 & 45.34 \\
\hline
\end{tabular}

were compared with the total shrinkage values, as shown in Table 4 . In the drying condition, the proportion of autogenous shrinkage was higher. With the increase of age, though autogenous shrinkage value had a small increase, the proportion of autogenous shrinkage showed a decreasing trend as a whole. According to the model calculation results and the previous theoretical analysis, it was obvious that the autogenous shrinkage and drying shrinkage both existed and restricted each other in drying condition. The hydration reaction of the cementitious materials and the water loss carried out simultaneously in the early age caused relatively clear shrinkage. With the density of structure, limiting the water loss, the development of drying shrinkage was inhabited in some degree; simultaneously, a large number of microporous was formed, and autogenous shrinkage gradually developed. Hydration reaction gradually slowed down while the water lost constantly later, which limited the development of autogenous shrinkage. From the late shrinkage development in Figure 1, it indicated that the drying shrinkage became the main factor after 28 days.

\section{Conclusion}

In the sealing, soaking, and drying conditions, the shrinkage of UHPFRC shows a rapid growth in the early stage and a gradual slowdown in the later stage. According to the mechanism, the early-age shrinkage of UHPFRC is divided into three parts: chemical shrinkage caused by hydration, autogenous shrinkage caused by self-drying, and drying shrinkage caused by water loss. Based on the basic theory of hydration and capillary tension, the key control factors and calculation methods of chemical shrinkage, autogenous shrinkage, and drying shrinkage are proposed, respectively.

Based on the determination results of the hydration degree of UHPFRC, the chemical shrinkage model is established. Based on the pore characteristics of the hardened paste, the hydration degree, and the determination results of the relative humidity, the autogenous shrinkage model is established by introducing the effective pore coefficient. The proportion of autogenous shrinkage to total shrinkage is basically stable between $45 \%$ and $49 \%$ in $28 \mathrm{~d}$ curing. According to the measured shrinkage of soaking specimens, the shrinkage value in soaked, sealing, and drying conditions is calibrated.

\section{Data Availability}

The data used to support the findings of this study are available from the corresponding author upon request.

\section{Conflicts of Interest}

The authors declare that they have no conflicts of interest.

\section{Acknowledgments}

This research was supported by National Natural Science Foundation of China (51408037 and 51578049), Major Scientific and Technological Projects of the Communications Ministry (2011318494160), and China Communications Construction R\&D Project (2013-ZJKJ-11).

\section{References}

[1] P. Y. Yan, The Development and Research Situation of UHPC, China Concrete, Hunan University, Changsha, China, 2010.

[2] B. A. Graybeal, "Material property characterization of ultrahigh performance concrete," Tech. Rep. FHWA-HRT-06-103, United States Department of Transportation, Washington, DC, USA, 2006.

[3] B. Graybeal, "Material property characterization of ultra-high performance concrete," Creep, vol. 1, pp. 887-894, 2007.

[4] H. Wang, S. Han, A. N. Mingzhe et al., "Development of microcosmic study on reactive powder concrete materials," Materials Review, vol. 28, pp. 95-53, 2014.

[5] S. Han, Y. Q. Tu, M. Z. An et al., "The shrinkage of reactive powder concrete in early age and its control methods," China Railway Science, vol. 36, no. 1, pp. 40-47, 2015.

[6] S. Han and J. Plank, "Mechanistic study on the effect of sulfate ions on polycarboxylate superplasticisers in cement," $A d$ vances in Cement Research, vol. 25, no. 4, pp. 200-207, 2013.

[7] A. C. L. Wong, P. A. Childs, R. Berndt et al., "Simultaneous measurement of shrinkage and temperature of reactive powder concrete at early-age using fiber Bragg grating sensors," Cement and Concrete Composites, vol. 29, no. 6, pp. 490-497, 2007

[8] T. Ishida, P. Chaube, T. Kishi et al., "Micro physical approach to coupled autogenous and drying shrinkage of concrete," in Proceedings of Intern Workshop on Autogenous Shrinkage of Conrete, JCI, pp. 301-312, June 13-14, Hiroshima, Japan.

[9] S. Y. Cao, "Study on autogenous shrinkage characteristic and mechanism of ultra-high performance cementitious composite," Bulletin of the Chinese Ceramic Society, vol. 3, p. 48, 2015.

[10] W. Huang, H. Kazemi-Kamyab, W. Sun et al., "Effect of cement substitution by limestone on the hydration and microstructural development of ultra-high performance concrete (UHPC)," Cement and Concrete Composites, vol. 77, pp. 86-101, 2017.

[11] S. Han, P. Y. Yan, and X. M. Kong, "Study on the compatibility of cement-superplasticizer system based on the amount of free solution," Science China Technological Sciences, vol. 54, no. 1, pp. 183-189, 2011.

[12] J. Zhang, D. Hou, and Y. Gao, "Uniform driving force of autogenous and drying shrinkage of concrete," Tsinghua Science and Technology, vol. 50, no. 9, pp. 1321-1324, 2010.

[13] S. Han, P. Y. Yan, and R. G. Liu, "Study on the hydration product of cement in early age using TEM," Science China Technological Sciences, vol. 55, no. 8, pp. 2284-2290, 2012.

[14] M. Bouasker, P. Mounanga, P. Turcry et al., "Chemical shrinkage of cement pastes and mortars at very early age: effect of limestone filler and granular inclusions," Cement and Concrete Composites, vol. 30, no. 1, pp. 13-22, 2008. 
[15] P. Lura, F. Winnefeld, and S. Klemm, "Simultaneous measurements of heat of hydration and chemical shrinkage on hardening cement pastes," Journal of Thermal Analysis and Calorimetry, vol. 101, no. 3, pp. 925-932, 2010.

[16] T. C. Powers, "Structure and physical properties of hardened Portland cement paste," Journal of the American Ceramic Society, vol. 41, no. 1, pp. 1-6, 2006. 


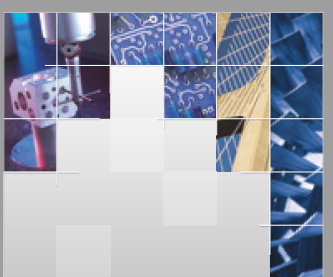

\section{Enfincering}
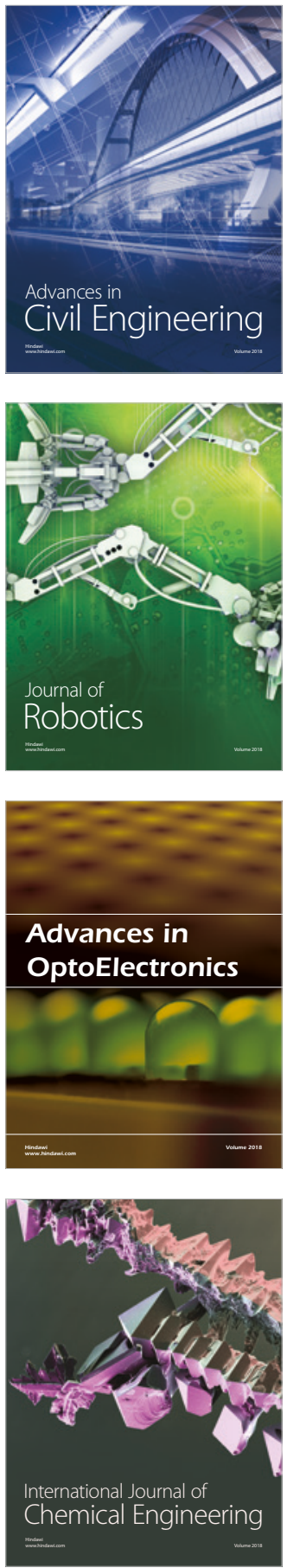

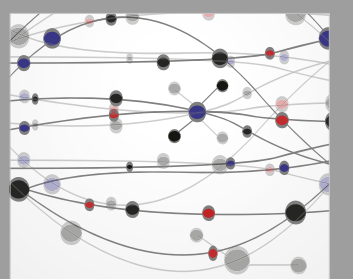

\section{Rotating \\ Machinery}

The Scientific World Journal

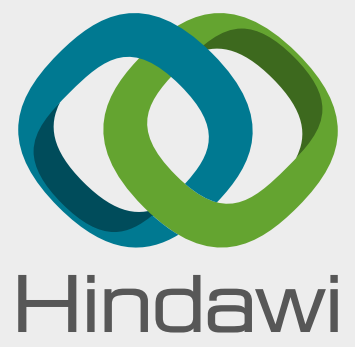

Submit your manuscripts at

www.hindawi.com
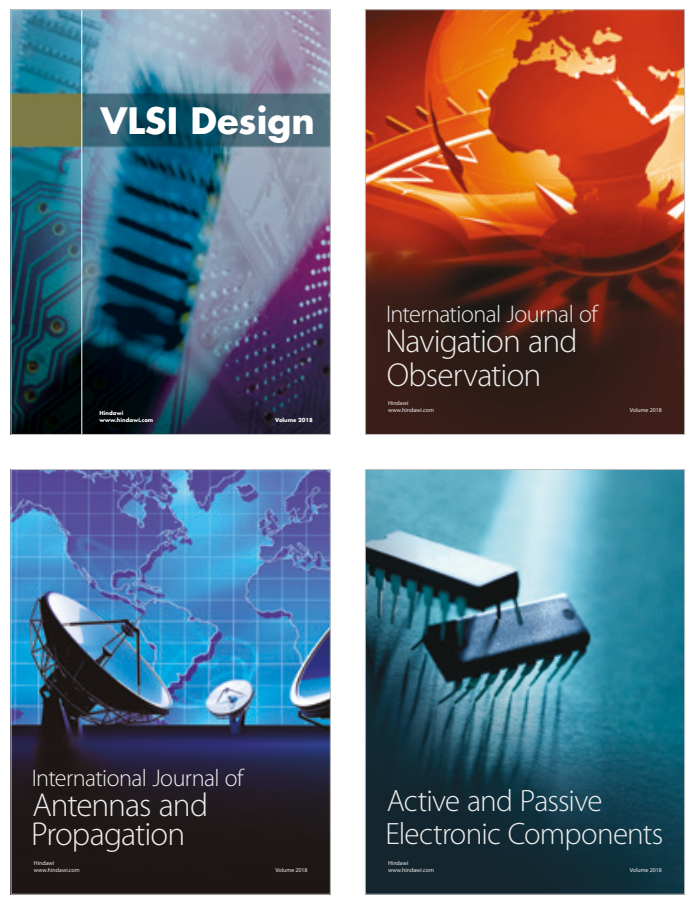
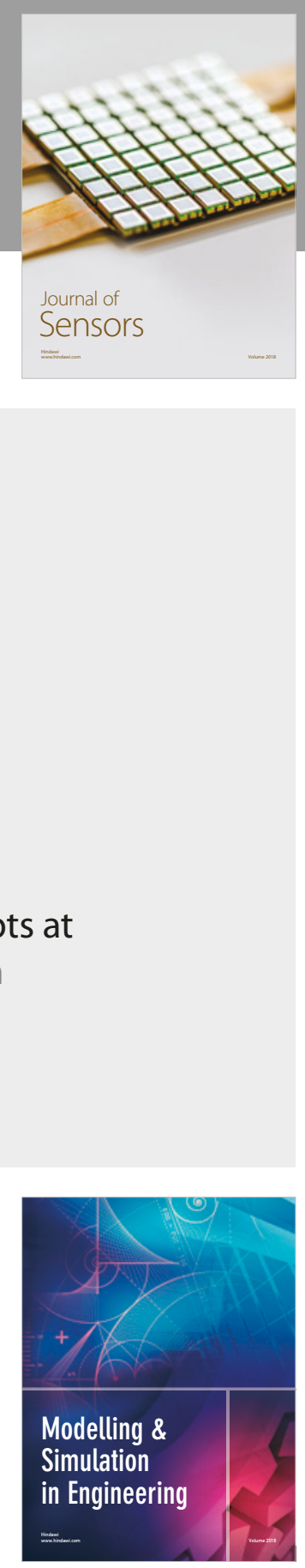

\section{Advances \\ Multimedia}
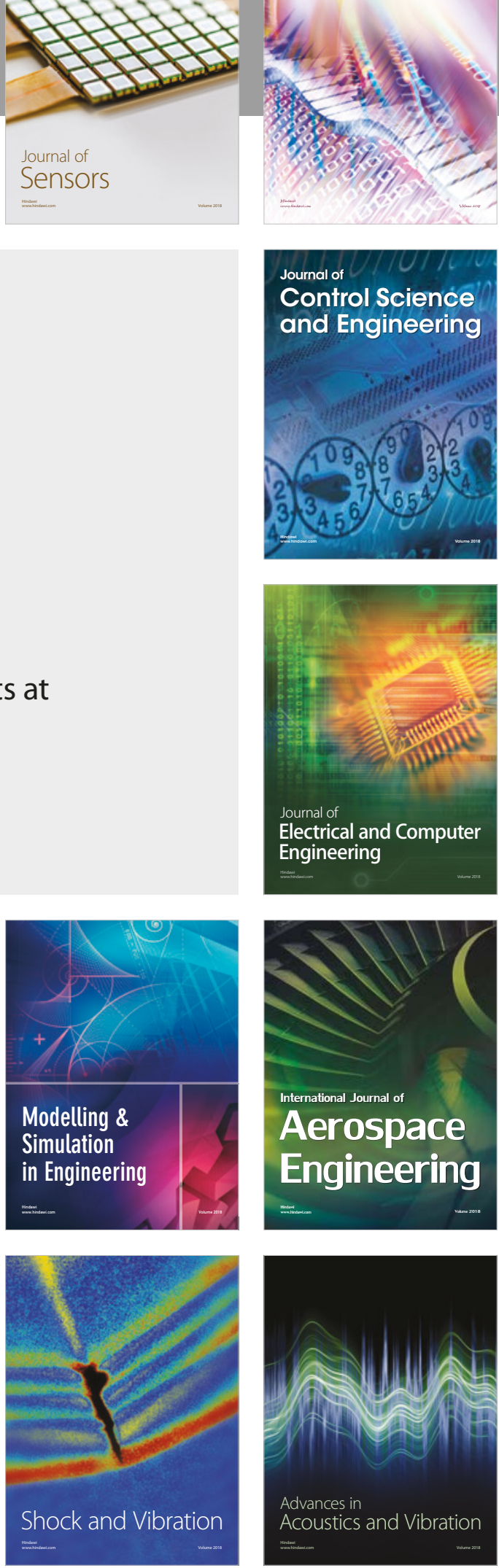